\title{
Seu óleo vira sabão: uma sequência didática para o ensino de Química Ambiental na educação profissional técnica em nível médio
}

\author{
Its oill becomes soap: a teaching sequence for teaching Environmental Chemistry in technical \\ professional education at mid-level
}

Su aceite se convierte en jabón: una secuencia didáctica para la enseñanza de la Química

Ambiental en la educación profesional técnica de nivel médio

Recebido: 05/08/2021 | Revisado: 10/08/2021 | Aceito: 27/08/2021 | Publicado: 29/08/2021

\author{
Joilson Silva Sampaio \\ ORCID: https://orcid.org/0000-0001-9412-4298 \\ Universidade Estadual de Santa Cruz, Brasil \\ E-mail: jssampaio@uesc.br \\ Alessandra Honorato Benfica Franco \\ ORCID: https://orcid.org/0000-0002-7784-3749 \\ Universidade Estadual de Santa Cruz, Brasil \\ E-mail: alessandrafilosofiauesc@gmail.com \\ Marcio Luís Oliveira Ferreira \\ ORCID: https://orcid.org/0000-0001-8724-5438 \\ Universidade Estadual de Santa Cruz, Brasil \\ E-mail:mloferreira@uesc.br \\ Elck Almeida de Carvalho \\ ORCID: https://orcid.org0000-0001-6832-6937 \\ Instituto Federal de Educação, Ciência e Tecnologia Baiano, Brasil \\ E-mail:biano.neto@gmail.com \\ Biano Alves de Melo Neto \\ ORCID: https://orcid.org0000-0001-6490-3274 \\ Instituto Federal de Educação, Ciência e Tecnologia Baiano, Brasil \\ E-mail:biano.neto@gmail.com
}

\begin{abstract}
Resumo
O objetivo deste trabalho foi desenvolver uma sequência didática para o ensino de química ambiental na educação profissional técnica em nível médio, tendo como premissas, ações pedagógicas e cidadã de inserção da consciência ambiental articuladas ao ensino de química. Para tanto, através de uma sequência didática estruturada em 9 (nove) etapas, foram realizadas inicialmente palestras de conscientização sobre o descarte inadequado de óleos comestíveis, campanhas de coleta de óleos, pesquisa, análises e melhoramento de receitas de fabricação de sabão, bem como a aquisição de equipamentos e insumos, com foco na produção de sabões visando doações em instituições, associações e comunidades carentes. Com o desenvolvimento deste trabalho, além do enriquecimento da prática pedagógica numa perspectiva mais concreta e socialmente responsável, foi possível apresentar à comunidade escolar, alternativas ao descarte dos óleos residuais, impulsionando uma mudança de postura e consciência ambiental, principalmente nas práticas laborais dos futuros técnicos em química, público alvo da sequência didática proposta. Também foi possível a realização de ações comunitárias de educação ambiental e de projetos envolvendo a comunidade escolar, resultando na publicação e distribuição gratuita de um livro de receitas de sabão, devidamente equilibradas.
\end{abstract}

Palavras-chave: Educação profissional; Oficinas de sabões; Educação Ambiental; Ensino.

\begin{abstract}
The objective of this work was to develop a didactic sequence for the teaching of environmental chemistry in technical professional education at high school level, having as premises, pedagogical actions and citizen insertion of environmental awareness articulated to the teaching of chemistry. To this end, through a didactic sequence structured in 9 (nine) steps, initially awareness lectures were held on the inappropriate disposal of edible oils, oil collection campaigns, research, analysis, and improvement of soap manufacturing recipes, as well such as the acquisition of equipment and supplies, with a focus on the production of soap for donations to institutions, associations and needy communities. With the development of this work, in addition to enriching the pedagogical practice in a more concrete and socially responsible perspective, it was possible to present to the school community alternatives to the disposal of residual oils, promoting a change in attitude and environmental awareness, especially in the working practices of future technicians in chemistry, the target audience of the proposed didactic sequence. It was also possible to carry out
\end{abstract}


community actions of environmental education and projects involving the school community, resulting in the publication and free distribution of a properly balanced soap recipe book.

Keywords: Professional education; Soap workshops; Environmental Education; Teaching.

\section{Resumen}

El objetivo de este trabajo fue desarrollar una secuencia didáctica para la enseñanza de la química ambiental en la educación técnica profesional a nivel de bachillerato, teniendo como premisas las acciones pedagógicas y la inserción ciudadana de la conciencia ambiental articulada a la enseñanza de la química. Para ello, a través de una secuencia didáctica estructurada en 9 (nueve) pasos, inicialmente se realizaron charlas de sensibilización sobre la disposición inadecuada de aceites comestibles, campañas de recolección de aceite, investigación, análisis y mejora de recetas de fabricación de jabón, así como la adquisición de equipos e insumos, con foco en la producción de jabón para donaciones a instituciones, asociaciones y comunidades necesitadas. Con el desarrollo de este trabajo, además de enriquecer la práctica pedagógica en una perspectiva más concreta y socialmente responsable, se logró presentar a la comunidad escolar alternativas a la disposición de aceites residuales, promoviendo un cambio de actitud y conciencia ambiental, especialmente en las prácticas laborales de los futuros técnicos en química, público objetivo de la secuencia didáctica propuesta. También fue posible realizar acciones comunitarias de educación ambiental y proyectos que involucren a la comunidad escolar, resultando en la publicación y distribución gratuita de un jabón debidamente equilibrado Libro de recetas.

Palabras clave: Educación professional; Talleres de jabón; Educación Ambiental; Enseñaza.

\section{Introdução}

Estima-se que o montante coletado de óleos vegetais usados no Brasil equivale a menos de $1 \%$ do total produzido, ou seja, 6 milhões e meio de litros de óleos usados. Os 99\% restantes são descartados, principalmente os utilizados para o preparo de alimentos, principalmente de frituras. Na maioria das vezes esse óleo é descartado inadequadamente, nos solos ou na rede de esgoto (Ecóleo, 2013; Moraes, Lima \& Santos, 2021).

Uma boa alternativa, para o óleo vegetal usado é reutilizar o óleo, minimizando o impacto causado pelo descarte inadequado do material. Uma das opções é produzir sabão (Oliveira, Carvalho, Castro \& Borges, 2021) a partir de óleo comestível de fritura usado, o que já vem sendo feito em casa, e que oferece riscos tanto na produção quanto no uso do produto, assim o consumidor pode doar o óleo usado para organizações não-governamentais, empresas, escolas, etc. Além do sabão, uma outra opção de reuso é a produção de Biodiesel se controlada a acidez desse resíduo (Tokarski, 2017; Pereira, Fernandes \& Bizerra, 2020).

A mudança de uma postura inconsequente frente a poluição diante do meio ambiente, sobretudo as causadas pelo descarte irregular dos óleos e gorduras residuais, tem se tornando cada vez mais necessária. Todos os países vêm sendo cobrados a assumirem uma postura sócio ambientalmente responsável, resultando em busca de alternativas em todas as áreas do conhecimento, bem como o estabelecimento da obsolescência de diversas práticas predatórias. Pinto (2016), enfatiza que a educação ambiental se propõe a ser um processo de formação dinâmico, permanente e participativo, no qual as pessoas envolvidas passem a ser agentes transformadores, participando ativamente da busca de alternativas para a redução de impactos ambientais e para o controle social do uso dos recursos naturais.

As Diretrizes Curriculares da Educação Básica evidenciam a necessidade de defesa do meio ambiente, econômico, político e cultural em relação às questões ambientais, de modo que a sociedade é componente e sujeita dessa problemática. Assim é essencial que os órgãos governamentais e educacionais criem condições e conhecimentos possibilitando a sociedade possa adquirir práticas de cidadania e preservação do meio ambiente (Brasil, 2013).

O ensino de química, bem como o das outras ciências, demanda um fazer pedagógico voltado para o desenvolvimento integral do educando, num esforço de capacitar cidadãos com consciência crítica com condições de modificar sua realidade de forma a transformá-la construtivamente. É através da reflexão sobre a prática que podem ser fortalecidas as situações de aprendizagem, para ampliar as possibilidades de contribuir com o conhecimento dos estudantes. O conhecimento e aprendizagem ocorre de fato através de um processo dialógico de construção e interação, para tanto o 
professor necessita desenvolver um conteúdo significativo em sala de aula estimulando situações desafiadoras envolvendo uma interação com os alunos e entre eles e conhecimento (Schmitt, 2011).

O grande desafio, posto para a sociedade é compatibilizar "desenvolvimento e ecologia", para tanto, Milaré (2016) propôs compatibilizar meio ambiente e desenvolvimento, considerando os problemas ambientais dentro de um processo contínuo de planejamento, atendendo-se adequadamente às exigências de ambos e observando-se as suas inter-relações particulares a cada contexto sociocultural, político, econômico e ecológico, dentro de uma dimensão tempo/espaço. Em outras palavras, isto implica dizer que política ambiental não se deve erigir em obstáculo ao desenvolvimento, mas sim em um de seus instrumentos, ao propiciar a gestão racional dos recursos naturais, os quais constituem a sua base material. Assim, a química deve ser um instrumento, para o qual a educação ambiental, deve ser vista como um processo contínuo de aprendizagem valorizando as diversas formas de conhecimento, o que conduz a conscientização de cidadãos com consciência local e planetária.

$\mathrm{Na}$ atualidade o ensino de química vive uma dicotomia onde a maior parte dos professores lida com um conceito não relacionado ao cotidiano dos alunos, isso torna distante a compreensão da situação problemática do ambiente. Nesse contexto, o professor passa a criar ambientes de aprendizagem com atividades diversificadas (Mota \& Rosa, 2018; Rosa \& Goi, 2020). Visando tornar o ensino de química mais concreto e relevante na vida das pessoas e estimular a ação cidadã em defesa do meio ambiente, desenvolver ações empregando óleos vegetais residuais e a reação de saponificação pode ser um diferencial tanto de conhecimento, quanto de preservação das reservas hídricas e do meio ambiente em si é o que reforça a relevância desta estratégia.

Kunzler e Schirmann (2011), ressaltam inúmeras iniciativas relacionadas ao processo de reciclagem de materiais, que implicam em benefícios tanto sociais quanto ambientais. Isso representa alternativas de renda para a população mais carente promovendo a inclusão social, assim diversos são os projetos de reciclagem e reaproveitamento de materiais, dentre eles destaca-se a reciclagem do óleo residual de cozinha para a fabricação de produtos como o sabão.

Desta forma, objetivou-se com esse trabalho desenvolver uma sequência didática para o ensino de química ambiental na educação profissional técnica em nível médio, tendo como premissas, ações pedagógicas e cidadã de inserção da consciência ambiental articuladas ao ensino de química, como norteador da formação do técnico em química.

\section{Metodologia}

\subsection{Caracterização da pesquisa}

A pesquisa foi desenvolvida no Centro Estadual de Educação Profissional em Gestão e Tecnologia da Informação Álvaro Melo Vieira (CEEP AMEV), escola pública da Rede Estadual da Bahia, localizada na região central do município de Ilhéus-Ba, escola essa que se dedica, exclusivamente, para formação profissional de nível médio, ofertante dos cursos Técnicos em: Química, Informática, Administração e Segurança Trabalho. Por se tratar também de um trabalho de pesquisa qualitativo (Ludke \& Andre, 2013), que visava o desenvolvimento da consciência ecológica através de uma mudança de postura da comunidade escolar do CEEP AMEV o, constituiu-se uma sequência didática, que partiu do descarte inadequado de óleo residuais de origem doméstica e comercial, apresentando, além dos prejuízos ao meio ambiente, alternativas para a destinação racional desses resíduos. A investigação acerca da aprendizagem de conceitos químicos referentes à estequiometria presentes na sequência didática, foi avaliada a partir da perspectiva dos alunos envolvidos (técnicos em química), considerando os pontos de vista técnicos, ambientais e sociais relevantes. 


\subsection{Sistematização da sequência didática proposta}

A sequência foi iniciada durante o $1^{\circ}$ (primeiro) semestre letivo de 2019, organizada em 9 (nove) etapas previstas para se estender durante o $2^{\circ}$ (segundo) trimestre letivo, onde as etapas se alternavam entre sala de aula, laboratórios e ações de campo. Com o objetivo de informar a comunidade escolar sobre os impactos ambientais causados pelo descarte inadequado de óleos, tanto na água quanto no solo e apresentar alternativa de coleta, reciclagem e possibilidade de empreendedorismo. A partir de formulações de sabão equilibradas, as etapas se estenderam até o $1^{\circ}$ (primeiro) semestre de 2020, potencializada pelas demandas análogas da pandemia COVID - 19.

O desenvolvimento foi viável graças ao apoio incondicional da gestão escolar disponibilizando os laboratórios, recursos, difusão publicitaria os parceiros citados na etapa 6 (seis), que deram a capilaridade regional necessária, e por fim, a Universidade Estadual de Santa Cruz (UESC), através do Programa de Mestrado Profissional em Química (PROFQUI), dando subsídios teóricos e de orientação no aprimoramento da pesquisa e efetividade conceitual dos princípios químicos.

\section{ETAPA 1: Óleo em Sabão}

Essa etapa foi realizada no dia 13 de abril de 2019, sábado letivo, com os alunos, e ocorreu em 2 (dois) momentos: a sensibilização realizada em sala de aula e a produção do sabão, que aconteceu no Laboratório de Ciências da escola.

\section{$1^{\circ}$ MOMENTO - Sensibilização}

Em sala de aula, foram apresentados slides detalhando os impactos ambientais, na fauna, flora e ecossistemas, causado pelo descarte inadequado de óleos residuais, atividade realizada no componente Biologia do curso. Em seguida, no componente Química, foram apresentados os processos químicos envolvendo a reação de saponificação. Ambos componentes, buscaram informar e sensibilizar os alunos para o envolvimento no projeto, que ao término dos componentes, assistiram um vídeo postado no link da plataforma YouTube ${ }^{\circledR}$, disponível no endereço https://www.youtube.com/watch? $\mathrm{v}=\mathrm{Mtb} 0 \mathrm{mUDX2sY}$, que mostrou a iniciativa de um restaurante que fornece os óleos doméstico para uma recicladora que coleta em toda grande Belo Horizonte - MG e tem com finalidade produzir, além de sabão, glicerina, tintas e até biocombustível, gerando emprego e renda.

\section{$2^{\circ}$ MOMENTO - Produção de sabão}

Ainda no mesmo sábado letivo da realização do $1^{\circ}$ (primeiro) momento, os alunos foram, com a orientação dos professores de Química, divididos em 4 (quatro) grupos de 6 (seis) integrantes, e no Laboratório de Ciências da escola desenvolveram experimentos de produção e análise de qualidade de sabão com óleos residuais descartado, produzindo uma receita de sabão líquido concentrado, escolhida de forma aleatória na internet, tendo como fonte de pesquisa a plataforma YouTube ${ }^{\circledR}$ (disponível no endereço https://www.youtube.com/watch?v=XfqE MotIOJg);

De posse das observações oriundas da oficina realizada no Laboratório de Ciências, foi discutida a estequiometria da reação de saponificação trazendo as referidas proporções, fundamentadas na Lei das proporções constantes (Lei de Proust), como também os agentes catalisadores da reação, que influenciaram na qualidade química da saponificação no intuito de apresentar futuras contribuições ao método, bem como o equilíbrio químico da reação e qualidade do produto.

\section{ETAPA 2: Análise do sabão}

Em sala de aula, de posse das observações oriundas da oficina realizada no Laboratório de Ciências, discutir a estequiometria da reação de saponificação trazendo para referidas proporções, fundamentadas na Lei das proporções constantes 
(Lei de Proust), como também os agentes catalisadores da reação, que influenciaram na qualidade química da saponificação no intuito de apresentar futuras contribuições ao método, bem como o equilíbrio químico da reação e qualidade do produto.

\section{ETAPA 3: Seminário de sensibilização}

Em sala de aula, de posse das observações oriundas da oficina realizada no Laboratório de Ciências, foi discutida a estequiometria da reação de saponificação trazendo pas referidas proporções, fundamentadas na Lei das proporções constantes (Lei de Proust), como também os agentes catalisadores da reação, que influenciaram na qualidade química da saponificação no intuito de apresentar futuras contribuições ao método, bem como o equilíbrio químico da reação e qualidade do produto.

\section{ETAPA 4: Campanha publicitária}

Nessa etapa os alunos, distribuídos nos grupos com 6 (seis) integrantes, foram desafiados a, com o apoio de um professor de marketing do curso de Administração, fomentar e buscar parcerias para construção de um produto midiático como cartaz, adesivos, vídeo e totem de coleta. Essa atividade visou extrapolar os muros da escola.

\section{ETAPA 5: Melhoramento da formulação}

De volta ao Laboratório de Ciências da escola, os mesmos grupos alunos, a partir do conhecimento dos conteúdos de estequiometria discutidos desde a segunda etapa, aprofundaram os conhecimentos de outras componentes curriculares de química, como soluções, química analítica e processos industriais trabalhados pelos demais professores em sala de aula. Assim, os grupos foram motivados a aprimorar e desenvolver novas receitas de sabões a partir de óleos e outros ácidos graxos residuais.

\section{ETAPA 6: Produção industrial}

Essa etapa foi realizada no Laboratório Fábrica de Sabão, situada na extinta Escola da Proa localizada no Bairro São Francisco, também no município de Ilhéus, visando o aprimoramento do método de produção de sabão líquido concentrado a partir dos estudos anteriormente realizados no Laboratório de Química.

\section{ETAPA 7: De sala em sala}

Nessa etapa os alunos envolvidos na pesquisa retornaram em todas as turmas da escola e apresentaram os produtos da campanha publicitária (convite, vídeo, adesivos e totem de coleta) Na oportunidade, eles falaram também sobre a importância da mesma, para o meio ambiente e a comunidade. Assim, os alunos visaram a intensificação na coleta de óleo e divulgação de instituições a serem beneficiadas pela doação da produção de sabão.

\section{ETAPA 8: O livro de receitas}

Nessa etapa, a cada grupo de alunos envolvido na pesquisa foi proposto pesquisar, construir e ou parametrizar até 3 (três) receitas existentes ou inéditas. Essas receitas juntas, seriam utilizadas na composição de um Livro de Receitas de Sabão (um produto desse trabalho) a partir de óleos e gorduras residuais, baseado nas aprendizagens de cálculos estequiométricos intensificados na $6^{\text {a }}$ (sexta) etapa da Sequência Didática. 
ETAPA 9: Doação de sabões

Essa etapa foi desenvolvida a partir da necessidade de higienizar e intensificar a higienização após a chegada da COVID19 na cidade de Ilhéus-BA. Alguns alunos, mesmo após já terem concluído ou estarem em conclusão do vínculo escola retornaram a unidade escolar, seguindo protocolos de segurança estabelecidos pela Organização Mundial de Saúde (OMS), para nos auxiliar na produção de sabão líquido e distribuição junto a comunidade e instituições filantrópicas.

\section{Resultados e Discussão}

\subsection{A Sequência Didática}

A Sequência Didática oportunizou uma quebra de paradigma em cada uma de suas etapas no momento em que a cada etapa houve ruptura e ou tornou concreto os saberes. Um dos pontos a serem destacados, foi ter trazido para a pesquisa, a ação dos professores de ciências da natureza, que se constituiu em um enriquecimento do planejamento da área, como também, os alunos, que cumpriu um outro papel, para além dos objetivos da pesquisa, o aperfeiçoamento prático dos futuros técnicos em química, já que os mesmos eram concluintes do curso, e devido a restrito campo de estágio, o fizeram nessa ação.

\section{ETAPA 1: Óleo em sabão}

Tornar um sábado letivo mais eficiente e produtivo, tendo em vista que muitos alunos apresentam desinteresse ou fadiga em vir à escola no sábado, já seria um motivo para o êxito do projeto, mas os dois momentos ali vivenciados possibilitaram muito mais.

Do ponto de vista didático, pode-se considerar o mesmo eficiente e produtivo, com descrito por Gasparin (2012), "há que se descobrir em consequência, maneiras de como os conhecimentos escolares têm força e peso nas mudanças sociais e pô-los em prática em função disso", ao argumentar sobre as dinâmicas incentivadoras para melhor aproveitamento dos sábados letivos, já que Moraes (2009) afirma que o conhecer e o aprender são processos de coparticipação que se dá na interação entre sujeitos, numa perspectiva sócio-cultural. Aprendemos e damos significado ao mundo no intercâmbio com nossa cultura e com nosso ambiente social.

Desta forma, no $1^{\circ}$ momento foi possível trazer adeptos para causa ambiental a partir da percepção da degradação humana em seu ecossistema, ver seus conhecimentos sendo úteis para a sociedade, perceber a viabilidade empreendedora do processo e, além tudo isso, vislumbrar a perspectiva de extrapolar os muros da escola nos momentos vindouros.

O empreendedorismo, de acordo com Schaefer \& Minello (2017), pode ser visto como algo que vai além da maneira convencional de aprender, uma forma de aprender com o desenvolvimento de habilidades de um empreendedor, tais como comunicação, criatividade, capacidade de reconhecer oportunidades, pensamento crítico, liderança e habilidade na tomada de decisões. Assim, percebe-se que esse $1^{\circ}$ momento conseguiu despertar nos alunos envolvidos, um pensamento empreendedor, importante para a formação.

No tocante ao $2^{\circ}$ momento, o êxito poderia ser descrito apenas na possibilidade de vivenciar o laboratório, entretanto, esse etapa foi além, pois apresentou-se a ação do profissional técnico no exercício de sua profissão ao perceberem que a experimentação vai além dos modelos preestabelecidos nos roteiros de aulas práticas e que suas experiências davam conta de serem úteis para problemas dia a dia.

Esse momento da Sequência Didática proposta coaduna com Cordão \& Moraes (2018), uma vez que o mesmo afirma que a atual Educação Profissional requer, além do domínio operacional de uma determinada atividade, uma visão global do processo produtivo, consequentemente a compreensão desde o saber tecnológico até a valorização da cultura do trabalho. 


\section{ETAPA 2: Análise do sabão}

Muitos sabões caseiros apresentam sua composição desequilibrada devido à falta de conhecimento ou instrumentos de análise. De acordo com Agência Nacional de Vigilância Sanitária Anvisa (2012) produtos com medidas de pH igual ou superior a 11,5 são considerados irritantes e corrosivos para pele, podendo ocasionar danos como ressecamentos, eritemas e dermatoses (Brasil, 2012) Voltando aos parâmetros necessários e as experiências descritas nos livros de química analítica, esse momento proporcionou confrontar as necessidades com os métodos preestabelecidos na Química, demonstrando por parte dos envolvidos uma maior segurança no cotidiano vindouro da profissão. A partir desse momento, a pesquisa participativa assumiu um perfil de pesquisa aplicada, visto que objetivou trazer inovações ao produto a ser parametrizado posteriormente em laboratório, conforme metodologia proposta por Gil (2002).

\section{ETAPA 3: Seminário de sensibilização}

Apresentar em forma de seminário em todas turmas da unidade escolar, possibilitou dar ao projeto a devida relevância, como também trazer com esses alunos o envolvimento da comunidade escolar como um todos de certo modo de seus familiares, já que neste momento suscitou a possibilidade de coleta para processamento na "Fábrica de Sabão".

Trazer a comunidade para essas questões, só foi possível uma vez que os seminários foram realizados de forma contextualizada e de maneira que os conteúdos abordados, através de um diálogo que buscou estimular vivências e dificuldades cotidianas o que fez sentido em suas realidades, além de ter sido demonstrado a possibilidade de agregação de valor aos envolvidos. Assim, conforme Santos \& Toschi (2015); Lima (2009), quando são aliados o trabalho ambiental e questões da sociedade, pode-se dizer que foi constituído um trabalho no âmbito socioambiental, trabalho esse fundamental para a formação cidadã.

\section{ETAPA 4: Campanha publicitária}

Nesta etapa (Figura 1), foi possível extrapolar a química, grande conquista, uma vez que trouxe para a sociedade, a relevância de tudo aquilo que se aprendeu numa profissão, hora marginalizada pela dinâmica da indústria, hora obscura pela “dificuldade" de compreensão dos seus conceitos. Para além disto, foi possível explorar uma área totalmente diferente e atrativa, pela sua notabilidade, sendo considerado algo desafiador e enriquecedor.

Figura 1. Campanha publicitária.
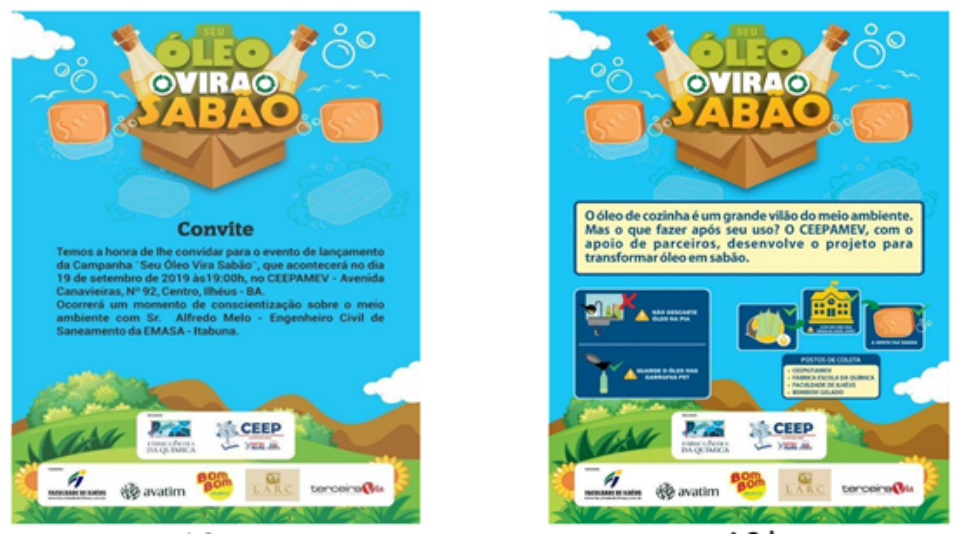

Fonte: Autores.

Os alunos foram promovidos no ambiente escolar, como diz Candau (2012, p. 247), [...] cada estudante "possa ser sujeito de sua vida e ator social", o que implica na promoção de práticas que os façam assim se reconhecerem. Com a 
execução desta etapa da Sequência Didática, foi possível também, a inserção de outros agentes apoiadores locais, como Larc Advocacia, Terceira Via Formaturas, Faculdade de Ilhéus e Bombom Gelados. Desta forma, foram constituídos, a escola e os dois últimos parceiros como pontos de coleta e a escola como responsável pelo processamento do óleo doméstico residual e transformação do mesmo em sabão.

\section{ETAPA 5: Melhoramento da formulação}

Nesta etapa, os alunos retornaram ao Laboratório de Química da escola e aprimoraram receitas de sabão líquido. Essa atividade trouxe para os alunos um estabelecimento seguro da profissão que escolheram, sem perder o foco principal para o qual foram desafiados, melhorar/proteger o meio ambiente. Consequentemente, permitiu ao aluno vivenciar o desenvolvimento de experiências inovadoras, que, segundo Pillon, Techio \& Baldessar (2020), produzem benefícios imediatos ao conhecimento dos conteúdos pedagógicos estudados, alinhando a prática com a teoria.

Ainda nesta etapa, durante o desenvolvimento das atividades laborais foram demonstradas algumas reações químicas, as quais foram exibidas em apresentação de PowerPoint e acompanhadas por uma simulações computacionais, onde foram evidenciadas pelo comportamento dos átomos na ocorrência das transformações químicas estudadas.

Essa interligação de conteúdo é importante para a melhoria do aprendizado e formação do profissional de química, como exposto por Dias et al, (2020), visto que a química é uma ciência experimental, então torna-se imprescindível a exploração do campo visual. Para ele esse recurso possibilita a manipulação de vários tipos de experiências. A realização de práticas experimentais reforça tanto o conteúdo que estiver sendo trabalhado quanto outras estratégias de ensino (Dias, et al, 2020).

Foi percebido então, que os alunos participaram e questionaram mais, sendo possível assim, estabelecer uma melhor composição de sabão líquido, melhor equilibrada quimicamente, definindo-se o padrão de aproveitamento dos resíduos de óleos processadas pela escola, onde para cada batelada de sabão, utilizou-se $6 \mathrm{~L}$ de óleo de residual (filtrado); $750 \mathrm{~g}$ de hidróxido de sódio em escamas 96/99\%, diluído a $50 \%$; 1,5 L de etanol (combustível); $25 \mathrm{~L}$ de água (fervente); e, ao término para ajustar a estequiometria da reação, $50 \mathrm{~g}$ de hidróxido de sódio a $50 \%$.

ETAPA 6: Produção industrial

Essa etapa se deu do final do mês de junho/2019, estendendo-se até início do mês de setembro/2019, caracterizando-se como a etapa mais longa do estudo realizado (Figura 2). 
Figura 2. Produção industrial.
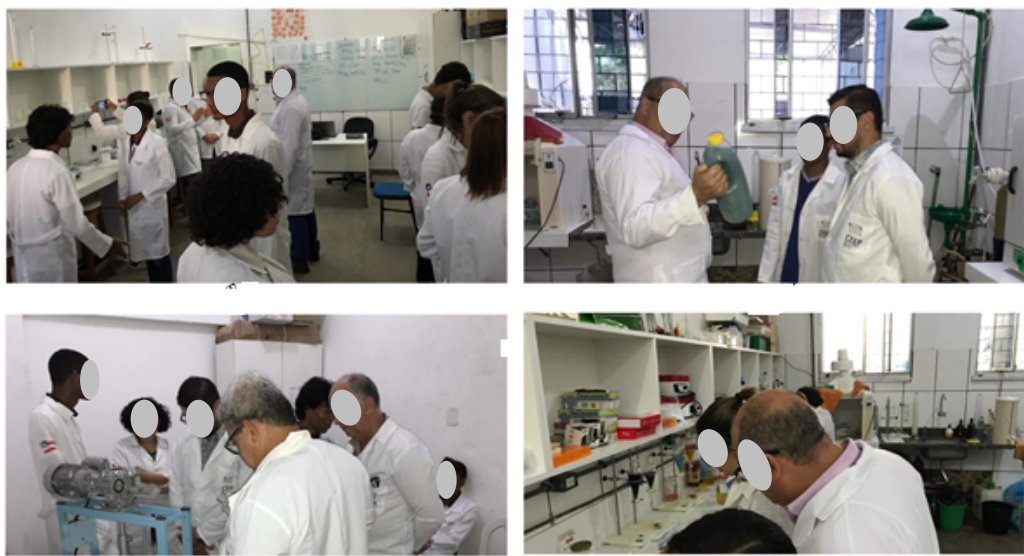

Fonte: Autores.

Foi durante a produção industrial, que os alunos passaram a perceber que, além de aprender química, proteger o meio ambiente, a produção de sabão, a partir dos óleos domésticos residuais, também ser algo rentável e eficiente, garantindo a perspectiva empreendedora, suas e dos seus, corroborando com Klauck e Brodbeck (2010), que fala que o desenvolvimento global em vários setores da sociedade como: tecnológico, produção e consumo, são processos que ocorrem de maneira desordenada causando grandes danos ao meio ambiente. Assim, aprimorar os métodos de coleta, filtragem, produção e envasamento visam mitigar essa problemática.

Nas Figura 2, pode-se observar que os alunos envolvidos tiveram a oportunidade de vivenciar na prática fabril, as potencialidade de usar o conhecimento teórico na autonomia da prática laboral, como também de superar as dificuldades de processamento do produto, aliando os conhecimentos teóricos de química, trabalhados na Sequência Didática proposta, através de conhecimentos do dia a dia, além disso, foi possível também, a interdisciplinaridade, haja vista que foram realizados cálculos de porcentagem, regras de três, simples e compostas, para estabelecimentos das formulações, como também cálculos de rendimento e custos de produção, agregando aos conhecimentos de química, a matemática financeira, entre outros.

Nessa perspectiva interdisciplinar, Zabala (1998) afirma que para facilitar o desenvolvimento do aluno é necessário utilizar o processo dinâmico e integrador de trabalhos grupo, potencializando o maior número de intercâmbios em todas as direções, a produção científica será mais ou menos rica conforme as possibilidades veiculadas pelas sequências didáticas. Assim o ambiente escolar tende a promover vias comunicativas de aprendizagem, buscar a ampliação fazer dos saberes através de estruturas abrindo o leque de possibilidades das relações de aprendizagem entre os diferentes atores do grupo, ou entre diferentes grupos, possibilitando assim aos grupos tornaram-se a corresponsáveis com a finalidade do conviver e do aprender.

\section{ETAPA 7: De sala em sala}

Nesta Etapa os alunos do $3^{\circ}$ ano e química irem em todas as demais turmas da escola possibilitou o crescimento, tanto na divulgação quanto na adesão, do projeto reforçando a importância da temática Educação Ambiental, que se estabelece como um processo permanente, no qual os indivíduos e a comunidade tomam consciência do seu meio ambiente e adquirem conhecimentos, valores, habilidades, experiências e determinação que os tornem aptos a agir e resolver problemas ambientais, presentes e futuros (Rua \& Souza, 2010). 
Etapa 8: O livro de receitas

Nesta etapa, os alunos foram motivados a transformar em um livro (Figura 3), as receitas de sabão estudadas, testadas, analisadas e produzidas, com objetivo de apresentar para a comunidade, receitas quimicamente equilibradas, que diminuísse o risco na fabricação, manuseio e uso dos sabões, além de ampliar a possibilidade de renda pelas famílias que já produzem esses sabões.

Figura 3. Livro de Receitas.

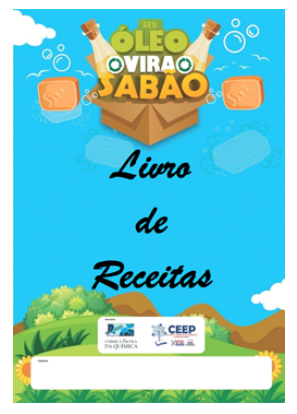

Fonte: Autores.

A entregar para comunidade escolar e acadêmica um produto (Livro de Receitas) que estabelece a interface entre os artesãos químicos e os acadêmicos foi algo imensurável, uma vez que o mesmo passou a apoiar nas bases teóricas e cuidados estabelecidos pelas normas de segurança industriais, utilizadas dentro e fora da escola, com uma linguagem acessível, que fazem da química um meio de subsistência às pessoas mais humildes.

Nesse sentido, desvelar os conceitos científico e acadêmico a partir dos conhecimentos oriundos do senso comum. Segundo Lopes (2001), há uma necessidade latente na educação brasileira de se resgatar a Química nos saberes populares, e no desenvolvimento dessa Sequência Didática, a "ciência" se tornou mais instigante para os aprendizes, sejam eles alunos, seja os aprendentes da comunidade envolvida. Corroborando com isso Lopes (2001, p. 1943), ainda afirma ser necessário fazer do conhecimentos populares, "preciso trabalhar criticamente a ciência do cientista, a ciência da escola e a ciência popular".

\section{ETAPA 9: Doação de sabões}

Esta etapa foi acrescida ao planejamento inicial do projeto, a partir dela atingiu de forma retumbante o objetivo de extrapolar os muros da escola pertencimento do projeto se demonstrou consolidado. Partindo do reconhecimento da Organização Mundial de Saúde (OMS) do estado de pandemia do COVID-19, o sabão líquido se tornou o principal meio de desinfecção e contenção da propagação do vírus, os alunos, em sua maioria já depois de formados, se voluntariaram a retornar a escola, visando a ampliação da produção de sabão a ser doados para auxiliar hospitais, ONGs, postos de saúde, corpo de bombeiros, abrigos, etc (Figura 4). 
Figura 4. Ação social.
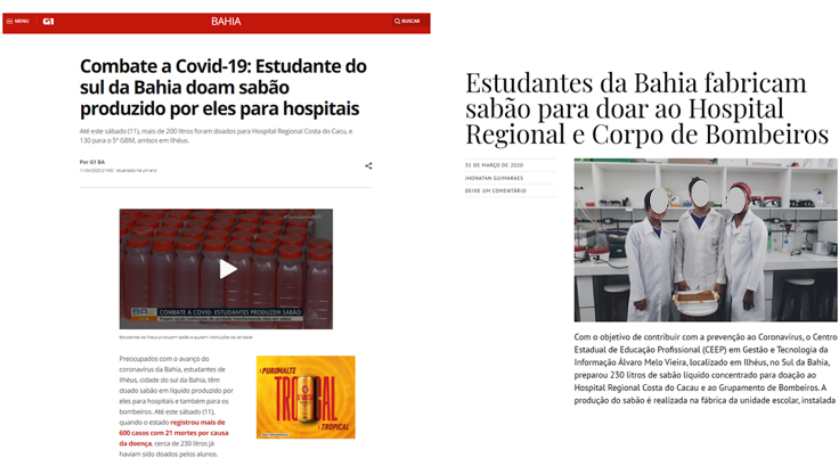

Fonte: Autores.

\section{Conclusão}

O desenvolvimento e aplicação da sequência didática proporcionou as turmas uma profunda reflexão em seu papel profissional e cidadão diante no meio ambiente, tanto no que diz respeito aos aspectos nocivos do descarte inadequado de óleos residuais, quanto ao seu papel profissional em encontrar soluções equilibradas para esses e outros tipos de resíduos, enquanto técnicos em química. Foi possível constatar que existem várias alternativas de utilização do óleo residual de fritura para obtenção de outros produtos com diferentes valores agregados, os quais podem envolver desde uma produção caseira, passando por associações e pequenas empresas até atingir grandes empresas. Os processos de produção de sabão e de produção podem ser implementados, conforme foi apresentado no presente trabalho. É importante que em projetos futuros, sejam realizadas análises detalhadas de viabilidade econômica desses tipo de produto, tendo em vista que foram encontrados poucos dados em literatura sobre o retorno econômico deste tipo de empreendimento utilizando óleo residual de fritura. O retorno dos alunos que participaram de oficinas e das instituições que receberam as doações, quanto à utilização dos sabões em práticas de limpeza (lavagem de louças e tecidos) foi bastante elogiada pela sua eficiência e superioridade até mesmo em comparação a alguns produtos comerciais. Com a publicação do livro, inspirar novas atitudes para a comunidade externa é uma tarefa muito construtiva, pois, para ensinar uma atividade prática com qualidade foi preciso pesquisar, testar e comparar os resultados, para se obter um produto atrativo e seguro ao público. Espera-se que essa receitas sejam seguidas, tanto pelos que tiveram oportunidade de participar da oficina, como também por aqueles que tiverem acesso ao projeto que está sendo divulgada no presente livro.

\section{Referências}

Anvisa. (2012). Guia para Avaliação de Segurança de Produtos Cosméticos. Boletim Técnico.

Ascom SE/UNA-SUS. (2020). Organização Mundial de Saúde declara pandemia do novo Corona vírus. https://www.unasus.gov.br/noticia/organizacaomundial-de-saude-declara-pandemia-de-coronavirus

Brasil, Ministério da Educação (2013). Diretrizes Curriculares Nacionais Gerais da Educação Básica / Ministério da Educação. Secretaria de Educação Básica. Diretoria de Currículos e Educação Integral. https://www.gov.br/mec/pt-br/media/seb/pdf/d_c_n_educacao_basica_nova.pdf

Brasil. Ministério da Educação (2014). Pacto nacional pela alfabetização na idade certa: alfabetização em foco: projetos didáticos e sequencias didáticas em diálogo com os diferentes componentes curriculares. http://www.serdigital.com.br/gerenciador/clientes/ceel/material/98.pdf

Candau, V. M. F. (2012). Diferenças culturais, interculturalidade e educação em direitos humanos. Educação \& Sociedade, 33(118), 235-250.

Cordão, F. A., \& Moraes. F. (2020). Educação profissional no Brasil: síntese histórica e perspectivas. Senac.

Dias, F. Y. E. C., Oliveira, R. D., Mendes, R. M. S., Pantoja, L. D. M., Bonilla, O. H., \& Chaves, B. E. (2020). O papel da Feira de Ciências como estratégia motivadora para o ensino de Botânica na educação básica. Hoehnea, 47. 1-10. 
Research, Society and Development, v. 10, n. 11, e197101119115, 2021

(CC BY 4.0) | ISSN 2525-3409 | DOI: http://dx.doi.org/10.33448/rsd-v10i11.19115

Ecóleo. (2013). Reciclagem. http://ecoleo.org.br/projetos/6766-2/

Gasparin, J. L. (2012). Uma Didática para a Pedagogia Histórico-Crítica. Editora Autores Associados Ltda.

Gil, A. C. (2002). Como elaborar projetos de pesquisa. Atlas.

Hauck Filho, Nelson. (2019). Editorial. Avaliação Psicológica, 18(1), 1-110

Jamil Cury, C. R. (2006). Entrevista - Educação Profissional: cidadania e trabalho. Boletim Técnico Do Senac, 32(1), 46-55.

Klauck, C. R., \& Brodbeck, C. F. (2010). Educação ambiental: um elo entre conhecimento científico e comunidade. Conhecimento Online, 1(2), 1-7.

Kunzler, A. A., \& Schirmann, A. (2011). Trabalho de Conclusão de Curso (TCC) na Tecnologia em Gestão Ambiental. Roca.

Lima, D. F. (2009). Projeto Político Pedagógico e Educação Ambiental uma necessária relação para a construção da cidadania. https://www.webartigos.com/artigos/projeto-politico-pedagogico-e-educacao-ambiental-uma-necessaria-relacao-para-a-construcao-da-cidadania/19621

Lima, J. F. \& Cordão, F. A. (2017). Desafios da Educação Profissional Técnica de Ensino Médio. B. Téc. Senac, 43(1), 78-109.

Lopes, A. C. (2003). Alfabetização Científica: questões e desafios para a educação. Revista Brasileira de Educação, 22, 171-173.

Ludke, M. \& Andre, M. E. D. A. (2013). Pesquisas em educação: uma abordagem qualitativa. E.P.U.

Milaré, É. (2016). Reação jurídica à danosidade ambiental: Contribuição para o delineamento de um microssistema de responsabilidade. Tese de Doutorado em Direito nas relações sociais. PUC-SP.

Moraes, M. E. B. \& Lorandi, R. (2009). Análise dos elementos da paisagem na bacia hidrográfica do Ribeirão do Pântano (SP) como subsídio ao zoneamento ambiental. Geografia, 34(3), 577-594.

Moraes, M. O., Lima, L. A. S., \& Santos, M. S. (2021). Uma alternativa para a reutilização do óleo de cozinha: aplicação da logística reversa favorecendo as questões ambientais. Research, Society and Development, 10(10), e381101019055.

Mota, A., \& Werner da Rosa, C. (2018). Ensaio sobre metodologias ativas: reflexões e propostas. Revista Espaço Pedagógico, 25(2), $261-276$.

Oliveira, B. A., Carvalho, L. P., Castro, G. C. O. \& Borges, D. G. (2021) Desenvolvimento de sabão líquido ecológico com propriedades coagulantes para purificação de águas residuais de manejo de suínos e sua aplicabilidade junto à comunidade. Research, Society and Development, 10(10), e406101018006.

Pereira, A. W., Fernandes, P. R. D. \& Bizerra, A. M. C. (2020). A produção de sabão como recurso pedagógico para o ensino de funções orgânicas. Research, Society and Development, 9(2), e84922119.

Pillon, A. E., Techio, L. R., \& Baldessar, M. J. (2020). O ensino híbrido (blended learning) como metodologia na educação atual: o caso de uma instituição de ensino superior do norte do estado de Santa Catarina. Brazilian Journal of Development, 6(6), 40731-40743.

Pinto, A. C. B. (2016). Educação ambiental na perspectiva da melhoria sócio-espacial: reflexões a partir do projeto "Caia na Rede" implantado na comunidade do Bate Facho - Salvador-BA. http://ri.ucsal.br:8080/jspui/handle/123456730/121

Rosa, A. P., \& Goi, M. E. J. (2020). A utilização de textos de divulgação científica no ensino de Química. Research, Society and Development, 9(6), e123963480.

Rua, E. R., \& Souza, P. S. A. (2010). Educação ambiental em uma abordagem Interdisciplinar e contextualizada por meio das disciplinas Química e Estudos Regionais. Química Nova na Escola, 32(2) 95-100.

Santos, J., \& Toschi, M. (2015). Vertentes da Educação Ambiental: da conservacionista à critica. Fronteiras: Journal of Social, Technological and Environmental Science, 4(2), 241-250.

Schaefer, R., \& Minello, I. F. (2017). Mentalidade Empreendedora: O Modo de Pensar do Indivíduo Empreendedor. Revista de Empreendedorismo e Gestão de Pequenas Empresas, 6(3), 495-524.

Schmitt, T. A. (2011). Considerações metodológicas atuais na análise fatorial exploratória e confirmatória. Journal of Psychoeducational Assessment, 29(4), 304-321.

Tokarski, D. (2017). Perspectivas do Setor de Biodiesel Brasileiro. https://fgvenergia.fgv.br/sites/fgvenergia.fgv.br/files/arquivos/4_donizete_ubrario_0.pdf Zabala, A. (1998). A prática educativa: como ensinar. ArtMed. 